\title{
Dependence of morphology of nanostructured nickel and cobalt powders on synthesis conditions
}

\author{
P.V. Lapsina ${ }^{1, \dagger}$, E.I. Kagakin ${ }^{2}$, A.N. Popova ${ }^{1,3}$, V.G. Dodonov ${ }^{3}$ \\ †lpv110185@rambler.ru \\ ${ }^{1}$ Kemerovo Scientific Center SB RAS, Russia, Kemerovo, Soviet pr., 18, 650000 \\ ${ }^{2}$ Kuzbass State Technical University, Russia, Kemerovo, Vesennyaya str., 28, 650000 \\ ${ }^{3}$ Institute of Coal Chemistry and Material Science SB RAS, Russia, Kemerovo, Soviet pr., 18, 650000 \\ ${ }^{4}$ Kemerovo State University, Russia, Kemerovo, Krasnaya str., 6, 650043
}

\begin{abstract}
The paper is devoted to study of the effect of synthesis conditions on size-characteristics of nanostructured nickel and cobalt powders. Metal nanopowders were obtained by chemical reduction of hardly soluble nickel and cobalt carbonates by hydrazine hydrate in aqua solutions. It is found that morphology (i.e. shape and size) of nanostructured metals powders is dependent on the synthesis conditions (concentration of the reducing agent, temperature, magnetic field). In the paper, it was shown the possibility of obtaining nanostructured powders of nickel and cobalt from the sparingly soluble salts. It was found that the optimum temperature range for the reduction of nickel and cobalt carbonate by mean of hydrazine hydrate is in the range of from 80 to $95^{\circ} \mathrm{C}$. Analysis of the whole complex data of the samples, obtained by SEM studies, shows that both nickel and cobalt powders synthesized by reduction of sparingly soluble carbonates are complex agglomerates with micron size consisting of nanoscale pieces. Nickel nanocrystals size depending on conditions varies in the range $17-23 \mathrm{~nm}$, cobalt - 23-33 nm. It has been found that the concentration of the reducing agent has a little influence on the size characteristics of the agglomerates and nanocrystallites metal powders. However, it was found that the application of a magnetic field could change shape and size characteristics of powders; this fact opens up the possibility of future using it to create a wide range of new functional materials. The phase composition and structure of the powders were studied by mean of X-ray powder diffractometer Bruker D8 ADVANCE A25. The morphology of powders was studied by scanning electron microscopy (SEM) on a scanning electron microscope JEOL JSM6390 SEM with an attachment for elemental analysis JED 2300, in addition to the complex study by X-ray diffraction methods. This work was carried out on the equipment of the Kemerovo Scientific Centre of SB RAS and the Kemerovo State University.
\end{abstract}

Keywords: nanostructured powders, nickel, cobalt, hydrazine hydrate, hardly soluble salts.

\section{Влияние условий получения на форморазмерные характеристики наноструктурированных порошков никеля и кобальта}

\author{
Лапсина П.В., ${ }^{1 \dagger}$, Кагакин Е.И. ${ }^{2}$, Попова А.Н. ${ }^{1,3}$, Додонов В.Г. ${ }^{4}$ \\ †lpv110185@rambler.ru
}

\begin{abstract}
${ }^{1}$ Кемеровский научный центр СО РАН, Россия, г. Кемерово, пр. Советский, 18, 650000
${ }^{2}$ Кузбасский государственный технический университет, Россия, г. Кемерово, ул. Весенняя, 28, 650000

${ }^{3}$ Институт углехимии и химического материаловедения, Россия, г. Кемерово, пр. Советский, 18, 650000

${ }^{4}$ Кемеровский государственный университет, Россия, г. Кемерово, ул. Красная, 6, 650043
\end{abstract}

В работе рассматривается влияние условий получения наноструктурированных порошков индивидуальных металлов никеля и кобальта методом химического восстановления труднорастворимых карбонатов. В качестве восстановителя используется водный раствор гидразингидрата. Установлено, что условия синтеза (концентрация восстановителя, температура, магнитное поле) определяют форморазмерные характеристики получаемых наноструктурирован- 
ных порошков. В работе показана возможность получения наноструктурированных порошков никеля и кобальта из малорастворимых солей. Выбран оптимальный температурный интервал восстановления карбонатов никеля и кобальта гидразингидратом, который находится в интервале от 80 до 95ㄷ. Анализ данных исследования образцов методом РЭМ показал, что все порошки никеля и кобальта, полученные восстановлением малорастворимых карбонатов, представляют собой сложные агломераты микронного размера, состоящие из нанометровых фрагментов. Размер нанокристаллитов никеля в зависимости от условий варьируется в диапазоне 17-23 нм, кобальта - 23-33 нм. Было установлено, что концентрация восстановителя слабо влияет на размерные характеристики агломератов и нанокристаллитов металлических порошков, полученных при восстановлении твердофазных прекурсоров. Однако наложением магнитного поля, можно изменять форморазмерные характеристики порошков, что открывает возможность их перспективного использования при создании широкого круга новых функциональных материалов. Для определения фазового состава и структуры порошки исследовали методами дифракции рентгеновских лучей на дифрактометре Bruker D8 ADVANCE A25. Исследования морфологии порошков проводили методом растровой электронной микроскопии (РЭМ) при помощи сканирующего электронного микроскопа JEOL JSM6390 SEM с приставкой для элементного анализа JED 2300, в дополнении с комплексом рентгеновских дифракционных методов. Работа выполнена с использованием оборудования Центра коллективного пользования КемНЦ СО РАН и КемГУ.

Ключевые слова: наноструктурированные порошки, никель, кобальт, гидразингидрат.

\section{1. Введение}

В настоящее время в развитых странах наблюдается быстрый темп развития современных технологий, что требует создания новых материалов с улучшенными свойствами и расширения областей их эффективного применения. Одним из наиболее важных и перспективных направлений в современной науке и материаловедении является синтез и исследование свойств наноструктурированных металлических порошков.

В последнее время, особенно большой интерес представляет получение нанопорошков переходных металлов, в частности, никеля и кобальта, ввиду их актуального практического применения. Наноструктурированные порошки никеля и кобальта, благодаря большой индукции насыщения, используются для создания магнитных жидкостей, материалов, используемых в системах записи и хранения информации, а также широко применяются в биологии и медицине [1-4].

Современные методы получения металлических наноструктур весьма разнообразны [5-9]. Однако ни один из существующих методов не является универсальным для регулирования как форморазмерных характеристик, так и химического и фазового составов. Среди существующих методов получения особо выделяют химические методы получения наноразмерных порошков металлов. Это связано с тем, что данный класс методов позволяет в широких пределах контролировать дисперсность, состав, стабильность получаемых порошков путем регулирования условий синтеза.

До настоящего времени химические способы получения наноструктурированных металлических порошков в основном ограничивались восстановлением водорастворимых солей $[10,11]$. Однако не меньший научный и технологический интерес представляет получение наноструктурированных порошков из твердофазных прекурсоров, практически нерастворимых в реакционной среде. Получение наночастиц металлов из труднорастворимых соединений металлов является перспективным направлением в связи с большей распространенностью таких соединений.

\section{2. Экспериментальная часть}

Наноструктурированные порошки никеля и кобальта получали восстановлением малорастворимых карбонатов соответствующих металлов избытком водного раствора гидразингидрата $[12,13]$. С целью изучения влияния условий синтеза на их форму и размер при получении металлических порошков никеля и кобальта варьировались следующие факторы: концентрация восстановителя, температура процесса, наложение внешнего постоянного магнитного поля (магнитная индукция 0,108 Тл) $[14,15]$. Полученные порошки промывались дистиллированной водой методом декантации, высушивались при комнатной температуре и хранились в герметичной полиэтиленовой таре.

Для определения фазового состава и структуры порошки исследовали методами дифракции рентгеновских лучей. Использовали дифрактометр Bruker D8 ADVANCE A25 в железном фильтрованном излучении ( $\mathrm{Fe}(\mathrm{K}$-альфа) излучение, $\lambda=0,19364$ нм). Исследования проводились в интервале углов $2 \theta 30^{\circ}-140^{\circ}$ с шагом сканирования $0.02^{\circ}$. Обработку дифрактограмм проводили с использованием пакета программ для сбора и обработки данных Diffrac.Suite.Eva (V3.1). Расшифровку дифрактограмм выполняли на основе базы данных ICDD PDF-2.

Измерения интенсивности малоуглового рассеяния проводили на установке КРМ-1 «на просвет» в железном характеристическом излучении $(\lambda(\mathrm{Fe})=0,19373$ нм $)$ посредством подсчета импульсов в отдельных точках. По кривым малоуглового рассеяния рассчитаны функции распределения частиц по размерам $\operatorname{Dm}(\mathrm{d})$ в приближении однородных сфер. Для компьютерной обработки данных (учет инструментальных искажений, расчет функций распределения, интегральных параметров дисперсной фазы) в работе использован пакет прикладных программ, разработанных в лаборатории рентгенографии кафедры ХТТ КемГУ $[16,17]$.

Исследования морфологии порошков проводили методом растровой электронной микроскопии (РЭМ) при помощи сканирующего электронного микроскопа JEOL JSM6390 SEM с приставкой для элементного анализа 
JED 2300, в дополнении с комплексом рентгеновских дифракционных методов (дифрактометры КРМ-1 и Bruker D8 ADVANCE A25).

Работа выполнена с использованием оборудования Центра коллективного пользования КемНЦ СО РАН и КемГУ.

\section{3. Результаты и обсуждение}

Рентгенофазовый анализ (РФА) показал, что образцы представляют собой рентгенографически чистые металлические никель и кобальт, не содержащие примесных окисных фаз. На рисунке 1 представлены дифрактограммы порошков никеля и кобальта.

Методом Селякова-Шеррера по уширениям дифракционных профилей были оценены размеры нанокристаллитов: для никеля в зависимости от условий размер нанокристаллитов варьируется в диапазоне 17-23 нм, для кобальта - 23-33 нм. Согласно результатам рентгенофлуоресцентного анализа содержание никеля в образцах составляет более 95 масс. \%, кобальта более 90 масс. \%, остальная доля приходится на кислород.

Анализ данных исследования образцов методом РЭМ показал, что все порошки никеля и кобальта, полученные восстановлением малорастворимых карбонатов, представляют собой сложные агломераты микронного размера, состоящие из нанометровых фрагментов. На рисунке 2 представлены электронные микрофотографии частиц полученных порошков.

Результаты исследования порошков никеля и кобальта методом РЭМ, хорошо согласуются с результатами исследования их методом малоуглового рассеяния рентгеновских лучей (МУРР). По данным МУРР функции распределения частиц никеля и кобальта по размерам имеют бимодальное распределение (рис.3). Первый пик функции распределения частиц, лежащий в области до 40 нм, характеризует размер нанокристаллитов. Второй пик, лежащий в области 0.1-0.7 мкм, характеризует размер агломератов исходных нанокристаллитов. Харак-

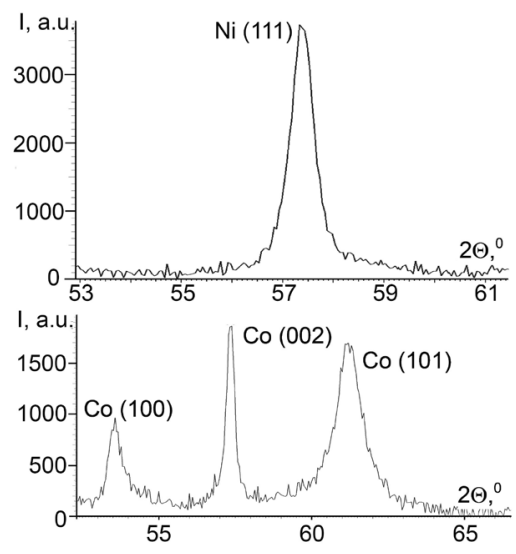

Рис. 1. Фрагменты рентгенограмм порошков никеля и кобальта, полученных при $95{ }^{\circ} \mathrm{C}\left(\mathrm{v}(\mathrm{N} 2 \mathrm{H} 4) / v\left(\mathrm{Ni}_{\mathrm{NiCO}_{3}}\right)=3.8\right.$; $\left.v(\mathrm{~N} 2 \mathrm{H} 4) / v\left(\mathrm{Co}_{\mathrm{CoCO}_{3}}\right)=25.6\right)$.

Fig. 1. Typical XRD patterns of nickel and cobalt nanopowders. терное бимодальное распределение частиц порошков сохраняется при варьировании условий синтеза (концентрации восстановителя, температуры).

При исследовании влияния концентрации гидразингидрата на эффективность процесса восстановления кристаллических солей до соответствующих металлов варьировали мольные соотношения восстановителя и металла в составе исходной соли $v(\mathrm{~N} 2 \mathrm{H} 4) / v\left(\mathrm{Me}_{\text {месоз }}\right)$ (где $\mathrm{Me}-\mathrm{Ni}, \mathrm{Co})$ в интервале: для никеля - $1-15$ и кобальта -7 - 68.

Согласно полученным результатам восстановление карбоната никеля до металлического никеля происходит уже при мольном соотношении гидразина и никеля в составе соли более 1.8. Для процесса восстановления карбоната кобальта до металлического кобальта отношение $v(\mathrm{~N} 2 \mathrm{H} 4) / v\left(\mathrm{Co}_{\mathrm{CoCO}}\right)$ составляет более 15.0. При уменьшении концентрации восстановителя в растворе наблюда-
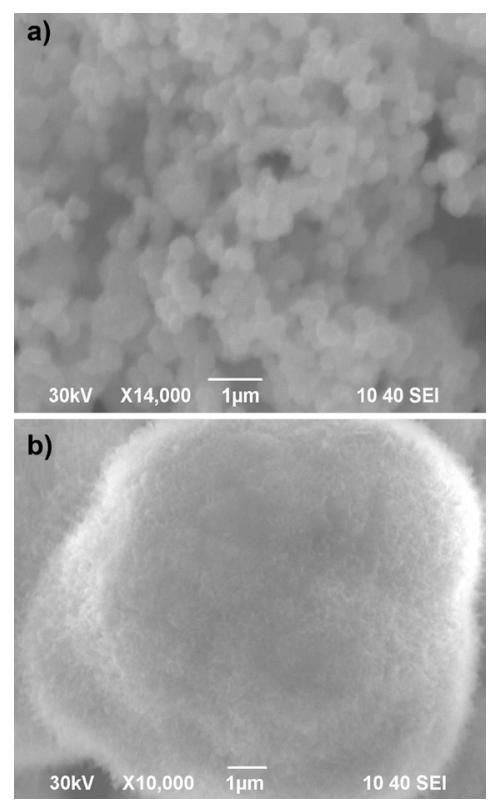

Рис. 2. Растровые электронные микрофотографии порошков никеля (а) и кобальта (b), полученных при $95^{\circ} \mathrm{C}$ $\left(v(\mathrm{~N} 2 \mathrm{H} 4) / v\left(\mathrm{Ni}_{\mathrm{NiCO}}\right)=3.8 ; v(\mathrm{~N} 2 \mathrm{H} 4) / v\left(\mathrm{Co}_{\mathrm{CoCO} 3}\right)=25.6\right)$.

Fig. 2. SEM image of nickel (a) and cobalt (b) nanopowders.

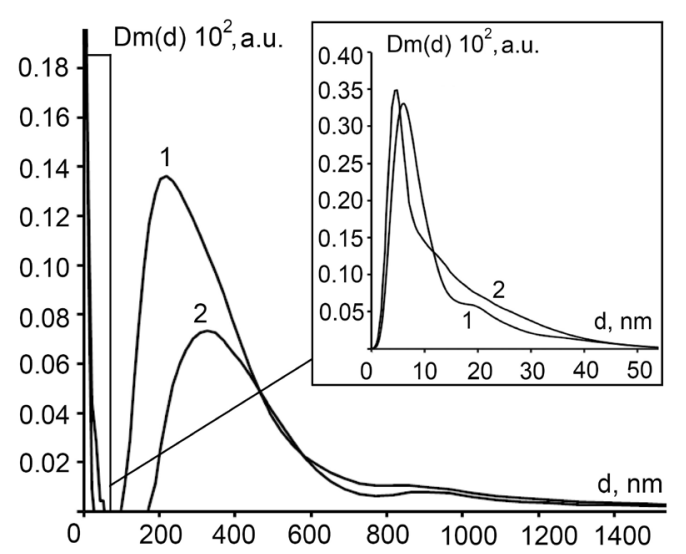

Рис. 3. Характерные массовые функции распределения частиц по размерам для никеля (1) и кобальта (2)

Fig. 3. Massive functions of particles size distribution for nickel (1) and cobalt (2) nanopowders. 
ется заметное замедление процесса восстановления, а также неполное восстановление исходных солей. Увеличение же мольного соотношения свыше 3.8 для карбоната никеля и 15.0 для карбоната кобальта не приводит к значительному повышению эффективности процесса как по полноте, так и по скорости.

В зависимости от количества гидразина для порошков никеля наблюдается уменьшение среднего размера агломератов $(d)$ и некоторое увеличение размера нанокристаллитов $\left(d_{0}\right)$ (Табл.1).

Для порошков кобальта концентрация восстановителя не оказывает существенного воздействия на средний размер агломератов и нанокристаллитов, наблюдается лишь тенденция к уменьшению этих размеров. Полученный результат показывает, что концентрация восстановителя слабо влияет на размерные характеристики агломератов и нанокристаллитов металлических порошков, полученных при восстановлении твердофазных малорастворимых прекурсоров.

Было изучено влияние температуры на процесс восстановления и форморазмерные характеристики порошков никеля и кобальта. При повышении температуры скорость восстановления заметно возрастает.

Таблица 1. Размерные параметры МУРР для порошков в зависимости от мольного соотношения восстановителя и металла в составе соли

Table 1. Particle size of nanopowders according to data of small-angle $\mathrm{X}$-ray scattering method

\begin{tabular}{|c|c|c|c|c|c|c|}
\hline \multirow{2}{*}{$№$} & \multicolumn{3}{|c|}{$\mathrm{Ni}$} & \multicolumn{3}{c|}{$\mathrm{Co}$} \\
\cline { 2 - 7 } & $\begin{array}{c}v(\mathrm{~N} 2 \mathrm{H} 4) / \\
v\left(\mathrm{Ni}_{\mathrm{NiCO} 3}\right)\end{array}$ & $\begin{array}{c}d_{0}, \\
\mathrm{~nm}\end{array}$ & $\begin{array}{c}d, \\
\mathrm{~nm}\end{array}$ & $\begin{array}{c}v(\mathrm{~N} 2 \mathrm{H} 4) / \\
v\left(\mathrm{Co}_{\mathrm{CoCO} 3}\right)\end{array}$ & $\begin{array}{c}d_{0} \\
\mathrm{~nm}\end{array}$ & $\begin{array}{c}d, \\
\mathrm{~nm}\end{array}$ \\
\hline \multirow{2}{*}{1} & 1.8 & 12.4 & 502 & 15.0 & 16.1 & 560 \\
\hline 2 & 3.8 & 11.4 & 416 & 25.6 & 13.9 & 503 \\
\hline 3 & 7.5 & 13.3 & 428 & 36.2 & 14.3 & 492 \\
\hline 4 & 9.4 & 15.0 & 462 & 46.9 & 14.1 & 524 \\
\hline 5 & 15.2 & 14.8 & 349 & 57.5 & 14.1 & 557 \\
\hline 6 & - & - & - & 68.2 & 14.0 & 505 \\
\hline
\end{tabular}

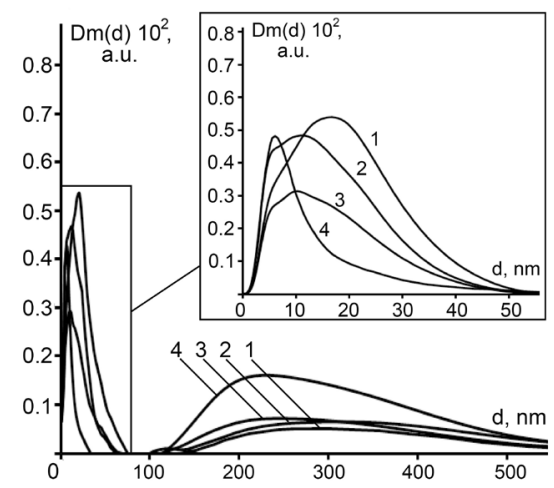

Рис. 4. Массовые функции распределения частиц никеля по размерам, полученных при температуре $30^{\circ} \mathrm{C}(1), 40^{\circ} \mathrm{C}(2), 60^{\circ} \mathrm{C}$ (3), $80^{\circ} \mathrm{C}(4)$.

Fig. 4. Massive functions of particles size distribution for nickel nanopowders synthesized at $30^{\circ} \mathrm{C}(1), 40^{\circ} \mathrm{C}(2), 60^{\circ} \mathrm{C}$ (3) and $80^{\circ} \mathrm{C}(4)$.
Результаты метода малоуглового рентгеновского рассеяния показывают, что дисперсная структура порошков никеля, полученных при различных температурах, характеризуется бимодальным распределением частиц по размерам (рис.4).

Аналогичные распределения характерны и для наноструктурированных порошков кобальта, получаемых химическим восстановлением малорастворимого карбоната. Первый пик функции распределения, соответствующий отдельным нанокристаллитам, с повышением температуры сужается и заметно смещается в сторону меньших размеров, при этом средний размер частиц уменьшается примерно в 2.5 раза. Второй пик, более широкий и пологий, находящийся в области 150-500 нм, имеет агрегационную природу и характеризует размеры агломератов исходных нанокристаллитов. При повышении температуры также наблюдается смещение положения второго максимума в сторону меньших размеров, хотя и незначительное.

С увеличением температуры для порошков никеля наблюдается уменьшение размеров агломератов, на размер частиц порошков кобальта увеличение температуры значительного влияния не оказывает. Оптимальный температурный интервал $80-95^{\circ} \mathrm{C}$.

Для проверки влияния магнитного поля на форморазмерные характеристики металлических порошков, полученных из труднорастворимых прекурсоров, был проведен эксперимент по восстановлению карбоната никеля гидразингидратом в постоянном магнитном поле. Эксперименты проводили при температуре $95^{\circ} \mathrm{C}$ в магнитном поле с магнитной индукцией 0,108 Тл.

Согласно результатам исследования МУРР частицы никеля, полученные в постоянном магнитном поле, характеризуются бимодальным распределением: фракция с размерами частиц до 40 нм и 150-800 нм (рис. 5, кривая 1). По сравнению с распределением частиц никеля, полученных в таких же условиях, но без наложения внешнего магнитного поля (рис. 5, кривая 2), агломерационный максимум массовой функции распределения частиц ни-

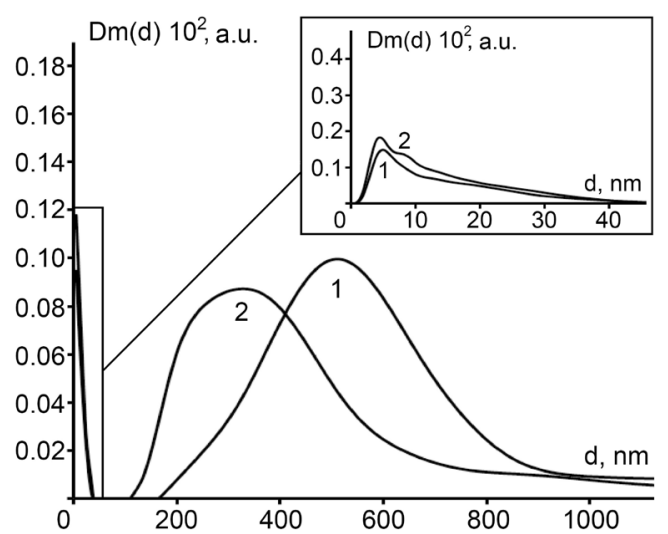

Рис. 5. Массовые функции распределения частиц по размерам для никеля, полученного в магнитном поле с индукцией $\mathrm{B}=$ 0,108 Тл при $\mathrm{T}=95^{\circ} \mathrm{C}(1)$ и без наложения магнитного поля при $\mathrm{T}=95^{\circ} \mathrm{C}(2)$.

Fig. 5. Massive functions of particles size distribution for nickel nanopowders synthesized at $95 \mathrm{C}$ at magnetic field $(\mathrm{B}=108 \mathrm{mTl})(1)$ and without magnetic field (2). 
келя, полученных в постоянном магнитном поле, имеет большую интенсивность и сдвинут в сторону больших размеров.

Наложение внешнего магнитного поля в процессе химического восстановления кристаллического карбоната никеля до металлического никеля способствует образованию агломератов со средним размером 500 нм, которые в свою очередь организуются в упорядоченные протяженные структуры, длиной до 1000 мкм (рис. 6).

\section{4. Заключение}

Создание материалов на основе наноразмерных порошков переходных металлов является интенсивно развивающимся направлением современного материаловедения.

В работе показана возможность получения наноструктурированных порошков никеля и кобальта из малорастворимых солей. Выбран оптимальный температурный интервал восстановления карбонатов никеля и кобальта гидразингидратом - 80-95 С. Размер нанокристаллитов никеля в зависимости от условий варьируется в диапазоне 17-23 нм, кобальта - 23-33 нм. Было установлено, что концентрация восстановителя слабо влияет на размерные характеристики агломератов и нанокристаллитов металлических порошков, полученных при восстановлении твердофазных прекурсоров. Однако наложением магнитного поля, можно изменять форморазмерные характеристики порошков, что открывает возможность их перспективного использования при создании широкого круга новых функциональных материалов.

Благодарность. Исследование выполнено при финансовой поддержке РФФИ в рамках научного проекта № 1403-31648 мол_a.

Acknowledgements. The reported study was supported by RFBR, research project No. 14-03-31648 mol_a.

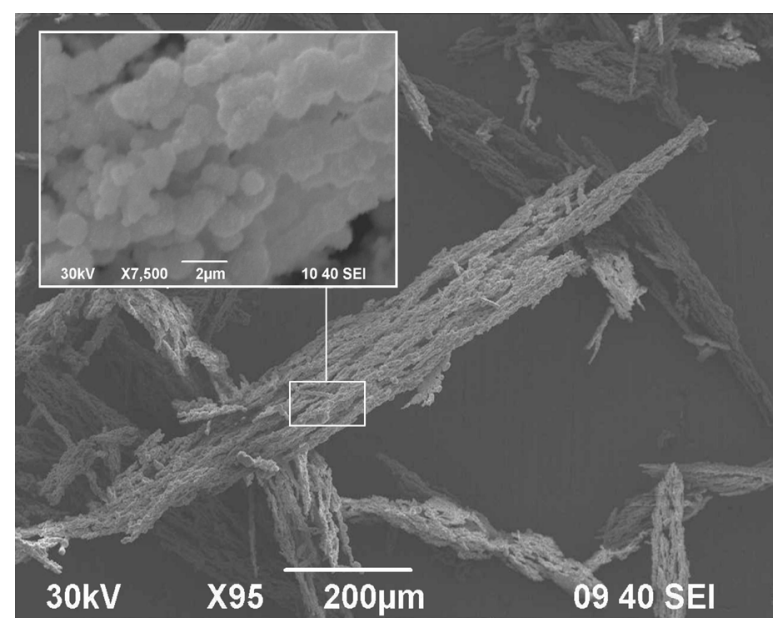

Рис. 6. Растровая электронная микрофотография металлических частиц никеля, полученных в магнитном поле.

Fig. 6. SEM image of nickel nanopowders synthesized at magnetic field.

\section{Литература / References}

1. M. Arruebo, R. Fernández-Pacheco, M.R. Ibarra, Jesús Santamaría. Nanotoday. 2 (3), 22 - 32 (2007).

2. G.S. Chaubey, C. Barcena, N. Poudyal, et al. J Am Chem Soc. 129, $7214-7215$ (2007).

3. Q. Nguen, C.N. Chinnasamy, S.D. Yoon, et al. J Appl Phys. 103, 07D532 (2008).

4. S. Peng, C. Wang, J. Xie, S. Sun. J Am Chem Soc. 128, 10676 - 11067 (2006).

5. A.S. Kurlov, A.A. Rempel, V.I. Matrenin, A.S. Stikhin. J. Inorg. Mat. 49 (2), 153 - 158 (2013).

6. A.N. Popova, Y.A. Zaharov, V.M. Pugachev. Mat. Let. 74, 173 - 175 (2012).

7. Z. Zhang, X. Chen, X. Zhang, C. Shi. 139 (8), 403 - 405 (2006).

8. A.N. Popova. J. of Physics: Conference Series. 345 (1), 012030 (2012).

9. V.P. Novikov, V.V. Pan'kov, L.I. Kunitskii. J. Inorg. Mat. 40 (8), $809-814$ (2004).

10. Y.A. Zakharov, V.M. Pugachev, V.V. Kriventsov, A.N. Popova. Bulletin of the Russian Academy of Sci.: Physics. 77 (2), 142 (2013).

11. Y.A. Zaharov, V.M. Pugachev, V.G. Dodonov, A.N. Popova. J. of Physics: Conf. Series. 345 (1), 012024 (2012).

12. P.V. Lapsina. Nanostructured powders of $\mathrm{Ni}$, Co and systems $\mathrm{Ni}-\mathrm{Co}$ obtained by reduction of hardly soluble carbonated by hydrazine hydrate in aqua solutions: Avtoreferat dissertacii na soiskanie stepeni kandidata himicheskih nauk - PhD-thesis abstract. Kemerovo. (2013) 20 p. (in Russian) [П.В. Лапсина. Наноструктурированные порошки $\mathrm{Ni}$, Со и системы $\mathrm{Ni-Co,} \mathrm{полученные} \mathrm{восстановлением} \mathrm{кристалличе-}$ ских карбонатов водным раствором гидразингидрата: автор-т дисс. канд. хим. наук. Кемерово. 2013. 20 с].

13. P.V. Lapsina, E.I. Kagakin, V.G. Dodonov. Izvestija Samarskogo nauchnogo centra Possijskoj akademii nauk. 14 (4-5), 1414-1417 (2012) (in Russian) [П.В. Лапсина, Е.И. Кагакин, В.Г. Додонов. Известия Самарского научного центра Российской академии наук. 14 (4-5), 1414-1417 (2012)].

14. E.I. Kagakin, P.V. Lapsina, V.G. Dodonov, V.M. Pugachev. Bulletin of Kemerovo State University. 4-1 (52), 264 267 (2012) (in Russian) [Е.И. Кагакин, П.В. Лапсина, В.Г. Додонов, В.М. Пугачев. Вестник Кемеровского государственного университета. 4-1 (52), 264 - 267 (2012)].

15. P.V. Lapsina, E.I. Kagakin, V.G. Dodonov, V.M. Pugachev, S.A. Sozinov. Polzunovskij vestnik. 3, 147 - 150 (2014) (in Russian) [П.В. Лапсина, Е.И. Кагакин, В.Г. Додонов, B.M. Пугачев. Ползуновский вестник. 3, 147 - 150 (2014)].

16. V.G. Dodonov. Z. Kristallogr. Suppliedissue. 4, 102 (1991).

17. V.G. Dodonov. Proceedings on IX International conference on radiation physics and chemistry of inorganic material, Tomsk. 139 - 140 (1996) (in Russian) [В.Г. Додонов. IX Международн. конф. по радиационной физике и химии неорганических материалов РФХ-9. Тез. докл. - Томск, 139 - 140 (1996)]. 